\title{
Fruit intake associated with urinary estrogen metabolites in healthy premenopausal women
}

\author{
Kerryn W. Reding ${ }^{1,2 *}$, Charlotte Atkinson ${ }^{3}$, Kim C. Westerlind ${ }^{4}$, Frank Stanczyk ${ }^{5}$, \\ Erin J. Aiello Bowles ${ }^{6}$, Mellissa Yong ${ }^{7}$, Katherine M. Newton ${ }^{6}$, Johanna W. Lampe ${ }^{2}$ \\ ${ }^{1}$ School of Nursing, University of Washington, Seattle, USA; ${ }^{*}$ Corresponding Author: kreding@uw.edu \\ ${ }^{2}$ Public Health Sciences Division, Fred Hutchinson Cancer Research Center, Seattle, USA \\ ${ }^{3}$ Lifecourse Epidemiology \& Population Oral Health Research, University of Bristol, Bristol, UK \\ ${ }^{4}$ Division of Endocrinology, Metabolism and Diabetes, University of Colorado Health Sciences Center, Denver, USA \\ ${ }^{5}$ Keck School of Medicine, University of Southern California, Los Angeles, USA \\ ${ }^{6}$ Group Health Research Institute, Seattle, USA \\ ${ }^{7}$ Center for Observational Research, Amgen, Inc., Thousand Oaks, USA
}

Received 16 October 2011; revised 27 November 2011; accepted 14 December 2011

\section{ABSTRACT}

Urinary concentrations of 2:16-hydroxyestrone (2:16-OHE $)_{1}$ approximate concentrations of 2-OHE and $16 a-\mathrm{OHE}_{1}$ in breast tissue. As estrogens are purported to be involved in breast cancer development, the 2:16-OHE $\mathrm{O}_{1}$ ratio can provide an indication of estrogen metabolite exposure in the breast. With prior studies observing associations between urinary estrogen metabolites and dietary intake of fruits, vegetables, and fiberascertained from food questionnaires, we examined associations between dietary factors ascertained through 3-day food records and urinary 2:16-OHE ${ }_{1}$ in 191 premenopausal healthy women. Fruit consumption was positively associated with $2: 16-\mathrm{OHE}_{1}$ after adjustment for total energy, ethnicity, body mass index, parity, smoking history, and serum estradiol $(p=0.003)$. Fruit consumption was positively associated with $2-\mathrm{OHE}_{1}$ concentrations $(p=0.006)$, but was not associated with $16 \alpha-\mathrm{OHE}_{1}(p=0.92)$. The Musaceae botanical grouping (comprised primarily of bananas) was positively associated with the 2:16-OHE 1 ratio, and Rosaceae (comprised of citrus fruits) and Musaceae botanical groupings were positively associated with $2-\mathrm{OHE}_{1}$ (but not $16 \alpha-\mathrm{OHE}_{1}$ ) concentrations, after adjustment for confounders. Our data suggest that dietary fruit intakeis associated with urinary $2-\mathrm{OHE}_{1}$ and the 2:16-OHE ${ }_{1}$ ratio and that breast tissue exposure to estrogen metabolites may thus be influenced by diet.

Keywords: Estrogen Metabolism; Diet; Botanical Groupings

\section{INTRODUCTION}

A large accumulation of evidence indicates that hormones, particularly estrogens, play a role in the development of breast cancer [1]. Estrogen metabolism begins with estradiol $\left(E_{2}\right)$ and estrone $\left(E_{1}\right)$ which can be hydroxylatedby cytochrome P450 enzymes at the 2,4 , and 16 carbon positions to form the 2-, 4- and 16 $\alpha$-hydroxy estrogens, respectively $[2,3]$. These estrogen metabolites are then inactivated by phase II enzymes, including UDPglucuronosyltransferase (UGT) and glutathione S-transferase (GST), quinonereductase $(\mathrm{QR})$, and sulfotransferase (SULT) enzymes [4-6]. With 2-hydroxyestrone (2--OHE 1 ) being shown to have weak binding to estrogen receptors (ER) and minimal genotoxic effects (in contrast with the 4-hydroxyestrogen [e.g. 4-OHE 1 and 4-OHE 2 ]), it has been viewed as the estrogen with the least biologic impact $[7,8]$. On the other hand $16 \alpha$-hydroxyestrone $(16 \alpha-$ $\mathrm{OHE}_{1}$ ), has been observed to strongly bind to ER $[9,10]$. With these contrasting qualities, the $2: 16-\mathrm{OHE}_{1}$ ratio has been proposed to be a marker for estrogenic effects in an individual. However, the link between breast cancer and $2: 16-\mathrm{OHE}_{1}$ has not been consistently observed [11-13]. Despite this, urinary measures of the $2: 16-\mathrm{OHE}_{1}$ ratio approximate the $2: 16-\mathrm{OHE}_{1}$ ratio $\mathrm{n}$ the breast-more so than the individual estrogen metabolites [14] indicating that urinary $2: 16-\mathrm{OHE}_{1}$ may provide clues as to the extent of estrogen exposure in the breast.

Research has sought to determine whether modifiable factors influence formation of certain estrogen metabolites. Prior studies indicate that estrogen metabolism may be altered in response to intake of certain dietary constituents, with support coming from laboratory studies, as well as human cross-sectional and intervention studies [6,15-25]. Of the cross-sectional studies investigating associations between a wide range of dietary factors and the 
2- and $16 \alpha-\mathrm{OHE}_{1}$ metabolites, a few have reported associations with fruit, vegetable, and coffee consumption, while one reported an association with high fat/low fiber diets [15-18]. Our study sought to investigate associations between urinary 2 - and $16 \alpha-\mathrm{OHE}_{1}$ metabolites and dietary factors ascertained through 3-day food records in 191 premenopausal healthy women.

\section{METHODS}

\subsection{Study Design}

Participants in the Equol, Breast, and Bone (EBB) study were recruited from the Group Health Cooperative (GHC), a large mixed-model health care system in western Washington State. The methods for this study have been described elsewhere [26]. Briefly, women were eligible if they were premenopausal, aged 40 to 45 years, and had received a screening mammogram at GHC prior to recruitment. Women were ineligible if they were currently using or had used hormone therapy or oral contraceptives for more than one month in the past year; had a personal history of breast cancer, or had shown signs of perimenopause.

After obtaining informed consent, EBB participants completed a health and demographics questionnaire. At the clinic visit, weight, height, waist and hip circumference measurements, percent body fat, and fasting blood and spot urine samples (during days 5 - 9 of their menstrual cycle) were collected. In addition, all participants were asked to complete a 3-day food record (3-DFR) within two weeks of this clinic visit. Participants were given a serving size booklet which contained pictures of commonly consumed foods in different portion sizes, as well as a ruler, a thickness guide, a serving spoon size guide, and tips on how to estimate servings. Dietary intake data from the 3-DFR were analyzed using the Nutrition Data System for Research software by the Nutrition Assessment Shared Resource at the Fred Hutchinson Cancer Research Center using previously described methods [26]. Estimates of daily intake of nutrients, grains, meats and shellfish, egg, dairy, tea and coffee, as well as botanically-defined groupings of fruits and vegetables were obtained.

\subsection{Laboratory Analysis}

The laboratory analysis for urinary $2-\mathrm{OHE}_{1}, 16 \alpha-\mathrm{OHE}_{1}$ and serum $\mathrm{E}_{2}$ have been described previously [27]. Briefly, concentrations of $2-\mathrm{OHE}_{1}$ and $16 \alpha-\mathrm{OHE}_{1}$ were measured in spot urine samples using a commercially available competitive, solid-phase enzyme-linked immunoassay (ESTRAMET, ImmunaCare Corp., Bethlehem, PA). Serum $E_{2}$ was quantified by radioimmunoassay after organic solvent extraction and Celite column partition chromatography [28]. Intra-assay and inter-assay coefficients of variation $(\mathrm{CV})$ for $2-\mathrm{OHE}_{1}$ were $4.4 \%$ and $8.8 \%$, respectively; for $16 \alpha-\mathrm{OHE}_{1}$ they were $5.1 \%$ and $9.2 \%$, respec- tively; and for serum $\mathrm{E}_{2}$, the inter-assay $\mathrm{CV}$ was $6.2 \%$.

Measurements of urinary creatinine concentrations were based on a kinetic modification of the Jaffe reaction with the use of the Roche Reagent for Creatinine (Roche Diagnostic Systems, Nutley, NJ).

\subsection{Statistical Analysis}

The ratio of 2:16-OHE 1 was computed from the concentrations of $2-\mathrm{OHE}_{1}$ and $16 \alpha-\mathrm{OHE}_{1}$. When analyzed separately, the 2- and $16-\mathrm{OHE}_{1}$ values were corrected for creatinine by dividing the estrogen metabolite concentration by the creatinine concentration. Lack of normality was assessed for each continuous variable; serum $\mathrm{E}_{2}, 2-\mathrm{OHE}_{1}$, and $16 \alpha-\mathrm{OHE}_{1}$ were skewed, and thus were log-transformed. Quartiles were created for the dietary factors, with the exception of the botanical groupings. For botanical groupings, analysis was limited to those groups that were consumed by at least $30(\geq 15 \%)$ participants. For those botanical groups, a variable was created that categorized participants as: not consuming the botanical grouping; those consuming less than the median value; and those consuming more than the median value.

For our primary analysis, we tested associations between the 2:16-OHE 1 ratio and dietary factors using generalized linear models (GLM) adjusted for potential confounding factors. A confounding factor was included in the GLM if it was statistically significantly associated with the 2:16$\mathrm{OHE}_{1}$ ratio (as determined using one-way ANOVA) and with dietary factors; all models included confounding factors (including serum $\mathrm{E}_{2}$, ethnicity and smoking history), in addition to total energy. Correlations were also examined between continuous variables using one-way ANOVA to ensure that variables with high correlations were not included in the same model.

To follow up on associations observed for fruit and vegetable consumption, we examined whether associations were observed between botanical groupings and 2:16- $\mathrm{OHE}_{1}$. In addition, to follow up on associations we observed between dietary factors and 2:16-OHE ${ }_{1}$ we used GLM to estimate the associations between dietary factors and the $2-\mathrm{OHE}_{1}$ and $16 \alpha-\mathrm{OHE}_{1}$ metabolites separately; these analyses were adjusted for creatinine, and total energy, in addition to confounding factors (ethnicity and smoking history). Benjamini-Hochberg correction was used to adjust for multiple testing in which adjustments were made according to the number of statistical tests for each hypothesis [29]. This analysis was conducted using Stata v. 11.

\section{RESULTS}

Demographic characteristics of the study population are presented in Table 1. The median age was 42.4 years; median body mass index (BMI) was $25.7 \mathrm{~kg} / \mathrm{m}^{2} .59 .4 \%$ of the women had a history of breast feeding and $64.6 \%$ were never smokers. 
Table 1. Demographic characteristics of the EBB study population.

\begin{tabular}{|c|c|c|}
\hline \multirow[t]{2}{*}{ Characteristic } & \multicolumn{2}{|c|}{$\mathrm{n}=191$} \\
\hline & mean & $\mathrm{SD}$ \\
\hline Age, years & 42.4 & 1.4 \\
\hline $\mathrm{BMI}, \mathrm{kg} / \mathrm{m}^{2}$ & 25.7 & 4.6 \\
\hline Height, cm & 165.0 & 6.8 \\
\hline Weight, kg & 70.1 & 13.4 \\
\hline \multirow[t]{2}{*}{ Waist:Hip ratio } & 0.79 & 0.06 \\
\hline & $\mathrm{n}$ & $\%$ \\
\hline Parous & 135 & 71.0 \\
\hline History of breast-feeding & 111 & 59.4 \\
\hline History of hormone use & 137 & 72.1 \\
\hline $\begin{array}{l}\text { First degree relative withbreast } \\
\text { and/or ovarian cancer }\end{array}$ & 24 & 24.7 \\
\hline \multicolumn{3}{|l|}{ Smoking status } \\
\hline Current & 8 & 4.0 \\
\hline Former & 62 & 31.3 \\
\hline Never & 128 & 64.6 \\
\hline \multicolumn{3}{|l|}{ Race/ethnicity } \\
\hline White & 166 & 87.4 \\
\hline Asian & 14 & 7.4 \\
\hline Other & 10 & 5.3 \\
\hline \multicolumn{3}{|l|}{ Years of school completed } \\
\hline$\leq 12$ & 12 & 6.3 \\
\hline $13-15$ & 49 & 25.8 \\
\hline 16 & 57 & 30.0 \\
\hline$\geq 17$ & 72 & 37.9 \\
\hline \multicolumn{3}{|l|}{ Income } \\
\hline$\leq \$ 49,999$ & 29 & 15.3 \\
\hline$\$ 50,000-\$ 75,000$ & 44 & 23.3 \\
\hline$>\$ 75,000$ & 90 & 47.6 \\
\hline Prefer not to answer & 26 & 13.8 \\
\hline
\end{tabular}

SD: Standard deviation.

We observed fruit and vegetable consumption to be positively associated with the $2: 16-\mathrm{OHE}_{1}$ ratio after adjustment for total energy, ethnicity, BMI, parity, smoking history, and serum $E_{2}$ (Table 2). In models adjusting for total energy only, the following dietary factors were associated with $2: 16-\mathrm{OHE}_{1}$ : total sugars $(\mathrm{p}=0.01)$, caffeine $(p=0.03)$, and refined grains $(p=0.03$; data not shown); however in the fully adjusted model, these factors were no longer associated with the $2: 16-\mathrm{OHE}_{1}$ ratio (Table 2). Furthermore, after adjustment for multiple tests only the association between $2: 16-\mathrm{OHE}_{1}$ and fruit consumption remained significant.
We observed two botanical groupings containing fruit to be positively associated with the $2: 16-\mathrm{OHE}_{1}$ ratio in the fully adjusted model (Table 3). Specifically, Rutaceae (e.g., citrus fruits and juices) and Musaceae (comprised primarily of bananas) were positively associated with $2: 16$ $\mathrm{OHE}_{1}$; however, after adjustment for multiple testing, the association for Rutaceae was no longer significant. Intake of fruit-containing botanical groupings ranged from 21.1\% of women consuming for Anacardiaceae (e.g., mangoes) to $85.6 \%$ for Rosaceae (e.g., apples, stone fruits, and some berries). $59.8 \%$ and $45.9 \%$ of women reported consuming Rutaceae and Musaceae, respectively. None of the botanical groupings for vegetables, including Cruciferae (which were consumed by $69.1 \%$ of women, although only $8.2 \%$ reported eating $>1$ serving/day), were associated with the $2: 16-\mathrm{OHE}_{1}$ ratio ( $\mathrm{p}$-value $=0.94$; data not shown).

We next assessed whether fruit or vegetable intake was associated with either $2-\mathrm{OHE}_{1}$ or $16 \alpha-\mathrm{OHE}_{1}$ separately using the same categorization for fruit and vegetables from Table 2 and for botanical groupings from Table 3. When assessed individually, neither fruit nor vegetable intake, including botanical groupings, were associated with $16 \alpha-$ $\mathrm{OHE}_{1}$ (Table 4). 2-OHE 1 was associated with overall fruit consumption and intake of Rutaceae and Musaceae botanical groupings, after adjustment for confounders. While overall fruit consumption and Musacea groupings were positively associated with $2-\mathrm{OHE}_{1}$, the pattern of association between Ruataceae and 2- $\mathrm{OHE}_{1}$ was less clear. The association between 2-OHE 1 and Rutaceae became stronger when confounders were included in the model, indicating an influence of ethnicity and smoking history on the relationships between consumption of foods in the Rutaceae grouping and 2-OHE . $_{\text {. }}$

\section{DISCUSSION}

We observed fruit consumption to be positively associated with the $2: 16-\mathrm{OHE}_{1}$ ratio among premenopausal women, and this was mostly due to its association with 2-OHE ${ }_{1}$ concentrations. We also observed that botanical food groupings containing citrus and bananas were associated with $2-\mathrm{OHE}_{1}$ concentrations. To our knowledge, this is the first study to examine the association between botanical groupings and $2: 16-\mathrm{OHE}_{1}$ in premenopausal women.

Our findings are biologically plausible given that dietary factors can influence phase I and phase II enzymes, and these enzymes act upon estrogen metabolites. Estroneishydroxylated into 2-, 4-, and $16 \alpha-\mathrm{OHE}_{1}$ by cytochrome P450 (CYP) enzymes. Specifically, CYP1A1 and CY$\mathrm{P} 1 \mathrm{~B} 1$ predominantly hydroxylate estrogens into 2 - and 4-OHE 1 , respectively, while CYP1A2 and CYP3A4 hydroxylate estradiol into $16 \alpha-\mathrm{OHE}_{1}$ [7]. Next, phase II enzymescan inactivate hydroxy estrogens, rendering them more easily excreted. Laboratory studies have demonstrated 
Table 2. Associations of nutrient and food groups with the urinary 2:16 hydroxy-estrone ratio.

\begin{tabular}{|c|c|c|c|c|c|}
\hline \multicolumn{6}{|c|}{$2: 16-\mathrm{OHE}_{1}$ ratio } \\
\hline & Q1 (95\% CI) & Q2 (95\% CI) & Q3 (95\% CI) & Q4 (95\% CI) & $\mathrm{p}$-value ${ }^{1}$ \\
\hline \multicolumn{6}{|l|}{ Nutrients ${ }^{2}$} \\
\hline Energy (kcal/d) & $1.6(1.3-1.8)$ & $1.7(1.5-2.0)$ & $1.6(1.4-1.8)$ & $1.7(1.3-2.1)$ & 0.80 \\
\hline Quartile cutoff points & $<1554$ & $1580-1870$ & $1874-2210$ & $2210-3184$ & \\
\hline Fat $(g / d)$ & $1.7(1.3-2.1)$ & $1.7(1.5-1.9)$ & $1.7(1.6-1.9)$ & $1.4(1.2-1.6)$ & 0.83 \\
\hline Quartile cutoff points & 56.3 & $56.9-69.7$ & $70.1-88.2$ & $88.2-148.3$ & \\
\hline Carbohydrate (g/d) & $1.5(1.3-1.7)$ & $1.7(1.4-1.9)$ & $1.7(1.5-1.9)$ & $1.7(1.4-2.1)$ & 0.80 \\
\hline Quartile cutoff points & $<176.4$ & $177.5-219.6$ & $219.7-265.3$ & $265.3-412.0$ & \\
\hline Total sugars (g/d) & $1.4(1.2-1.5)$ & $1.6(1.4-1.9)$ & $1.8(1.6-2.0)$ & $1.7(1.3-2.1)$ & 0.16 \\
\hline Quartile cutoff points & $<70.2$ & $70.5-90.4$ & $90.8-123.7$ & $124.8-275.1$ & \\
\hline Protein (g/d) & $1.6(1.4-1.8)$ & $1.7(1.5-1.9)$ & $1.5(1.3-1.7)$ & $1.8(1.4-2.2)$ & 0.88 \\
\hline Quartile cutoff points & $<62.5$ & $63.0-73.4$ & $75.7-91.0$ & $91.2-132.8$ & \\
\hline Total dietary fiber $(\mathrm{g} / \mathrm{d})$ & $1.6(1.3-1.8)$ & $1.7(1.4-1.9)$ & $1.5(1.3-1.7)$ & $1.8(1.5-2.2)$ & 0.80 \\
\hline Quartile cutoff points & $<13.0$ & $13.0-17.4$ & $17.4-22.5$ & $22.6-49.4$ & \\
\hline Caffeine (mg/d) & $1.6(1.3-2.0)$ & $1.6(1.3-2.0)$ & $1.6(1.4-1.9)$ & $1.8(1.5-2.0)$ & 0.09 \\
\hline Quartile cutoff points & $<71.1$ & $73.6-146.5$ & $147.4-213.6$ & $213.8-686.3$ & \\
\hline Alcohol (g/d) & $1.5(1.3-1.7)$ & $1.7(1.3-2.1)$ & $1.6(1.4-1.8)$ & $1.8(1.6-2.0)$ & 0.60 \\
\hline Quartile cutoff points & 0 & $0.003-0.2$ & $0.3-12.4$ & $12.4-50.4$ & \\
\hline \multicolumn{6}{|l|}{ Food Groups (servings/d) ${ }^{2}$} \\
\hline Fruit & $1.4(1.2-1.7)$ & $1.4(1.2-1.6)$ & $1.6(1.4-1.8)$ & $2.1(1.7-2.4)$ & 0.003 \\
\hline Quartile cutoff points & $<0.8$ & $0.8-1.5$ & $1.5-2.7$ & $2.7-12.0$ & \\
\hline Vegetables & $1.7(1.5-1.9)$ & $1.7(1.4-1.9)$ & $1.5(1.3-1.7)$ & $1.7(1.4-2.1)$ & $0.04^{\S}$ \\
\hline Quartile cutoff points & $<2.0$ & $2.0-2.9$ & $3.0-4.1$ & $4.1-10.6$ & \\
\hline Grains, refined & $1.5(1.4-1.8)$ & $1.9(1.7-2.1)$ & $1.7(1.3-2.1)$ & $1.5(1.3-1.7)$ & 0.20 \\
\hline Quartile cutoff points & $<2.6$ & $2.7-3.9$ & $3.9-5.2$ & $5.3-12.6$ & \\
\hline Grains, whole & $1.5(1.3-1.7)$ & $1.9(1.5-2.2)$ & $1.6(1.4-1.8)$ & $1.6(1.4-1.8)$ & 0.42 \\
\hline Quartile cutoff points & $<0.3$ & $0.4-0.9$ & $0.9-1.9$ & $2.0-5.6$ & \\
\hline $\begin{array}{l}\text { Red meat, game, poultry, } \\
\text { cold cuts and sausages }\end{array}$ & $1.6(1.4-1.9)$ & $1.6(1.4-1.8)$ & $1.6(1.3-1.8)$ & $1.8(1.4-2.2)$ & 0.64 \\
\hline Quartile cutoff points & $<3.4$ & $3.4-4.9$ & $4.9-6.5$ & $6.6-14.9$ & \\
\hline Fish and shellfish & $1.7(1.5-1.8)$ & $1.7(1.5-1.8)$ & $1.6(1.4-1.8)$ & $1.6(1.3-2.0)$ & 0.64 \\
\hline Quartile cutoff points & 0 & 0 & $0.03-1.1$ & $1.2-7.4$ & \\
\hline Eggs & $1.6(1.4-1.8)$ & $1.6(1.3-1.8)$ & $1.6(1.4-1.8)$ & $1.9(1.5-2.3)$ & 0.44 \\
\hline Quartile cutoff points & 0 & $0.01-0.3$ & $0.3-0.7$ & $0.7-2.6$ & \\
\hline Dairy foods & $1.7(1.4-2.1)$ & $1.6(1.3-1.8)$ & $1.6(1.4-1.9)$ & $1.7(1.5-1.9)$ & 0.91 \\
\hline Quartile cutoff points & $<1.3$ & $1.3-1.9$ & $2.0-2.9$ & $2.9-8.9$ & \\
\hline Tea and coffee & $1.6(1.3-2.0)$ & $1.5(1.3-1.7)$ & $1.9(1.6-2.2)$ & $1.6(1.4-1.8)$ & 0.22 \\
\hline Quartile cutoff points & $<0.7$ & $0.7-1.9$ & $1.9-3.0$ & $3.0-9.9$ & \\
\hline
\end{tabular}

p-value representing a test in trend across the quartiles with adjustment for total energy, ethnicity, BMI, parity, smoking status, serum free estradiol; ${ }^{2}$ From 3-day food records; ${ }^{\xi}$ No longer significant after adjustment for multiple testing. 
Table 3. Association between urinary 2:16-OHE 1 ratio and selected botanical groups.

\begin{tabular}{|c|c|c|c|c|c|c|c|c|}
\hline $\begin{array}{l}\text { Botanical } \\
\text { groupings }\end{array}$ & $\begin{array}{l}\text { Median consumption }{ }^{1} \\
\text { (servings/day) }\end{array}$ & Not consumed & & $\begin{array}{l}\text { Below median } \\
\text { intake }\end{array}$ & & $\begin{array}{l}\text { Above median } \\
\text { intake }\end{array}$ & & p-value ${ }^{2}$ \\
\hline Fruit & & $\mathrm{n}(\%)$ & $2: 16-\mathrm{OHE}_{1}$ & $\mathrm{n}(\%)$ & $2: 16-\mathrm{OHE}_{1}$ & $\mathrm{n}(\%)$ & $2: 16-\mathrm{OHE}_{1}$ & \\
\hline Rosaceae & 0.50 & $28(14.4)$ & 2.02 & $80(41.2)$ & 1.54 & $86(44.3)$ & 1.62 & 0.49 \\
\hline Musaceae & 0.38 & $105(54.1)$ & 1.47 & 44 (22.7) & 1.64 & $45(23.2)$ & 2.07 & 0.006 \\
\hline Rutaceae & 0.34 & $78(40.2)$ & 1.44 & $58(29.9)$ & 1.68 & $58(29.9)$ & 1.89 & $0.04^{\S}$ \\
\hline Ericaceae & 0.21 & $138(71.1)$ & 1.64 & $25(12.9)$ & 1.58 & $31(16.0)$ & 1.76 & 0.70 \\
\hline Curcurbitaceae & 0.20 & $81(41.8)$ & 1.66 & $56(28.9)$ & 1.59 & $57(29.4)$ & 1.69 & 0.40 \\
\hline Vitaceae & 0.16 & $121(62.4)$ & 1.64 & $36(18.6)$ & 1.59 & $37(19.1)$ & 1.73 & 0.20 \\
\hline
\end{tabular}

${ }^{1}$ Median level among those consuming at least one food categorized within the botanical grouping; ${ }^{2}$ Testing association with the 2:16-OHE 1 ratio, adjusted for total energy, ethnicity, BMI, parity, smoking status, serum free estradiol; ${ }^{\S}$ No longer significant after adjustment for multiple testing; ${ }^{* *}$ Limited to botanical groupings consumed by $\geq 15 \%$ of study population; Rosaceae: almond, apple, pear, strawberry, raspberry, apricot, plum, peach, blackberry, cherry, Juneberry, loganberry, nectarine, prune, quince, salmonberry, acerola, loquat; Musaceae: banana, plantain; Rutaceae: oranges, mandarin, grapefruit, kumquats, lemons, limes, tangerines; Ericaceae: blueberries, cranberries, huckleberries, lingonberries, oheloberries, wintergreen; Curcurbitaceae: melon, watermelon, cucumber, courgette, marrow pumpkin, squash, balsam-pear; Vitaceae: grapes.

Table 4. Associations between 2-hydroxyestrone, 16 $\alpha$-hydroxyestrone, and selected dietary factors.

\begin{tabular}{|c|c|c|c|c|c|}
\hline & \multicolumn{4}{|c|}{ Categories of consumption } & p-value ${ }^{3}$ \\
\hline \multicolumn{6}{|c|}{$2-\mathrm{OHE}_{1}^{4}(95 \% \mathrm{CI})$} \\
\hline \multicolumn{6}{|c|}{ Food Group ${ }^{1}$} \\
\hline Fruit & $0.6(0.4-0.8)$ & $0.6(0.4-0.9)$ & $0.7(0.5-0.8)$ & $1.0(0.5-1.4)$ & 0.006 \\
\hline Vegetables & $0.6(0.4-0.9)$ & $0.7(0.4-0.9)$ & $0.8(0.4-1.3)$ & $0.7(0.5-0.9)$ & 0.95 \\
\hline \multicolumn{6}{|c|}{ Botanical Group ${ }^{2}$} \\
\hline Rosaceae & $1.1(0.5-1.7)$ & $0.6(0.4-0.7)$ & $0.7(0.5-1.0)$ & & 0.86 \\
\hline Musaceae & $0.7(0.5-0.8)$ & $0.7(0.3-1.1)$ & $0.8(0.4-1.1)$ & & 0.01 \\
\hline Rutaceae & $0.8(0.5-1.0)$ & $0.6(0.4-0.8)$ & $0.8(0.4-1.1)$ & & 0.009 \\
\hline Ericaceae & $0.6(0.5-0.8)$ & $0.8(0.3-1.2)$ & $1.0(0.4-1.6)$ & & 0.08 \\
\hline Curcurbitaceae & $0.6(0.5-0.8)$ & $0.7(0.5-0.9)$ & $0.9(0.5-1.3)$ & & 0.54 \\
\hline Vitaceae & $0.7(0.5-0.9)$ & $0.8(0.4-1.2)$ & $0.6(0.3-1.0)$ & & 0.46 \\
\hline \multicolumn{6}{|c|}{$16 \alpha-\mathrm{OHE}_{1}^{4}(95 \% \mathrm{CI})$} \\
\hline & & Food Group $^{1}$ & & & \\
\hline Fruit & $0.4(0.3-0.6)$ & $0.5(0.3-0.7)$ & $0.4(0.3-0.6)$ & $0.4(0.3-0.6)$ & 0.92 \\
\hline Vegetables & $0.4(0.3-0.6)$ & $0.4(0.3-0.6)$ & $0.5(0.3-0.7)$ & $0.4(0.3-0.6)$ & 0.61 \\
\hline \multicolumn{6}{|c|}{ Botanical Group $^{2}$} \\
\hline Rosaceae & $0.5(0.3-0.8)$ & $0.4(0.3-0.5)$ & $0.5(0.3-0.6)$ & & 0.67 \\
\hline Musaceae & $0.5(0.4-0.6)$ & $0.4(0.2-0.6)$ & $0.4(0.3-0.5)$ & & 0.75 \\
\hline Rutaceae & $0.5(0.4-0.7)$ & $0.4(0.2-0.5)$ & $0.4(0.3-0.6)$ & & 0.31 \\
\hline Ericaceae & $0.4(0.3-0.5)$ & $0.5(0.2-0.7)$ & $0.5(0.3-0.8)$ & & 0.19 \\
\hline Curcurbitaceae & $0.4(0.3-0.5)$ & $0.4(0.3-0.5)$ & $0.5(0.3-0.7)$ & & 0.55 \\
\hline Vitaceae & $0.5(0.4-0.6)$ & $0.5(0.3-0.7)$ & $0.3(0.2-0.5)$ & & 0.81 \\
\hline
\end{tabular}

${ }^{1}$ Using quartiles; ${ }^{2}$ Using a categorical variable with 3 levels (no consumption, below and above the median consumption); ${ }^{3}$ Adjusted for total energy, ethnicity, smoking status, and creatinine; ${ }^{4}$ Normalized using creatinine levels. 
support for a role of diet in estrogen metabolism, showing that dietary factors can induce phase I enzymes involved in estrogen metabolism [6,19-25]. For example, several components of cruciferous vegetables, including isothiocyanatesand indole-3-carbinol (I3C), have been demonstrated in vitro to influence CYP enzymes [23,24]. More specifically, I3C binds to aryl-hydrocarbon recaptor (AhR), which binds to the xenobiotic response element on the promoter of CYP1A1, thereby inducing expression of CYP1A1 [23], and leading to increased 2-OHE concentrations. In addition, quercetin, a flavonoid found widely in fruit, vegetables, and grains (including citrus fruits and leafy greens), has been shown to also bind to AhR and induce CYP1A1 expression [20]. Furthermore, quercetin was observed to decrease CYP1A2 activity in vivo in both animal and human studies [6,21,22], which would conceivably lead to decreased $16 \alpha-\mathrm{OHE}_{1}$ concentrations.

Numerous phytochemicals, including quercetin and other flavonoids (including naringenin found in citrus fruits), have also been shown to influence the activity of phase II enzymes, including UGT, GST, QR, and SULT enzymes [4-6]. These relationships are complex, as flavonoids are demonstrated to induce some phase II enzymes, including multiple UGT enzymes and QR, while inhibiting others, such as SULT, but overall the influence of flavonoids on phase IIenzymes is consistent with chemoprevention.

Prior observational studies have reported on associations between dietary factors from questionnaire data and $2-\mathrm{OHE}_{1}$ and $16 \alpha-\mathrm{OHE}_{1}$ concentrations [15-18]. Reports include an inverse association between vegetable intake and $16 \alpha-\mathrm{OHE}_{1}$ [15], a positive association between foods rich in hydroxybenzoic acids (e.g. berries) and 2-OHE [15], an inverse association between low fat/high fiber and $16 \alpha-\mathrm{OHE}_{1}$ [17], and a positive association between coffee consumption and 2:16- $\mathrm{OHE}_{1}$ [18], all of which favorably alter the $2: 16 \alpha-\mathrm{OHE}_{1}$ ratio $[7,8,17]$. However, while most of these cross-sectional studies investigated similar dietary factors in relation to $2-$ and $16 \alpha-\mathrm{OHE}_{1}$, there were not entirely consistent findings across these studies.

Further support for the impact of dietary intake on estrogen metabolites come from human feeding and intervention studies. Feeding studies and interventions have also observed increased consumption of isoflavones (genistein and daidzein), flaxseed, I3C supplementation, and lowfat diets to be associated with increased $2-\mathrm{OHE}_{1}$ concentrations and the $2: 16-\mathrm{OHE}_{1}$ ratio in women [30-33], findings that are consistent with the in vitro studies discussed above. With flaxseed and berries being a good source of lignans [34], and our finding that fruit was associated with 2:16-OHE 1 , we investigated the potential for berries (botanical groupings Ericaceae and Rosaceae) to be associated with 2:16-OHE $\mathrm{H}_{1}$. Although we did not see evidence of an association between Ericaceae and Rosaceae and
$2: 16-\mathrm{OHE}_{1}$ it is possible that the levels of berry consumption were too low to detect associations and that lignans may actually contribute in part to fruit consumption being associated with $2: 16-\mathrm{OHE}_{1}$. Our study observed fruit intake to be associated with the $2: 16-\mathrm{OHE}_{1}$ ratio. While it is possible that these findings are spurious, the association between 2:16- $\mathrm{OHE}_{1}$ and fruit intake and the Musaceaegrouping remained significant after the correction for multiple tests. Furthermore, in the context of the aforementioned support from prior animal and human studies [15,16,20-22], this finding may have validity. The observed association between vegetables and $2: 16-\mathrm{OHE}_{1}$ should be interpreted with caution as these associations were not significant after correction for multiple testing, and as a result may be more likely due to chance.

Limitations of our study include the use of participant recall for dietary intake. While dietary assessment tools in general may misclassify dietary intake, a 3-day food record (which our study used) arguably has higher validity than a food frequency questionnaire, particularly for major food groups [35-37]. Another limitation centers on the issue of generalizability. The women in our study representa more health-conscious segment of the general population, with for example a mean BMI of 25.7 in our study and only $4 \%$ of participants being current smokers. Thus their dietary intake may not be representative of women from the US population as a whole. However, these characteristics may enhance the internal validity because confounding factors, such as cigarette smoking, are minimized in this rather homogeneous population. An additional limitation involves the use of a single spot urine collection for assessment of the 2- and $16 \alpha-\mathrm{OHE}_{1}$ concentrations. First, previous studies have indicated that there was no difference between a spot urine and a 24-hour urine for assessment of $2: 16-\mathrm{OHE}_{1}$ [38], and that urinary $2: 16-\mathrm{OHE}_{1}$ is correlated with plasma $2: 16-\mathrm{OHE}_{1}\left(\mathrm{r}^{2}=0.83\right.$ among nonOC users whose urine samples are collected mid-cycle, which matches our study's protocol) [39]. However, despite the high reproducibility of the assays for the 2- and $16 \alpha-\mathrm{OHE}_{1}$ as indicated by the low CVs, Williams et al. estimated that 5 collections would be ideal in order to capture the variability in urinary hydroxy estrogens [40]. Lastly, as with all cross-sectional studies, we were unable to assess the temporality of the diet and 2:16-OHE $\mathrm{O}_{1}$ association. However, a strength of cross-sectional studies are their ability to investigate a variety of food groups associated with 2:16- $\mathrm{OHE}_{1}$, and in the case of diet and 2:16-OHE multiple diet interventions have previously demonstrated that diet precedes changes in the $2: 16-\mathrm{OHE}_{1}$ [30-33]. Furthermore, investigation of associations with botanical groupings in particular allowed for an examination of specific sources of phytochemicals within the diet.

Our study adds to the large body of literature that indicatesdietary intake is associated with $2: 16-\mathrm{OHE}_{1}[6,15-25]$ 
in premenopausal women. With urinary $2: 16-\mathrm{OHE}_{1}$ representing the $2: 16-\mathrm{OHE}_{1}$ ratio in the breast [14], this line of research may have implications for modifiable factors related to breast cancer. However, while we observed that fruit consumption, including the botanical grouping Musaceae, was associated with increasing 2- $\mathrm{OHE}_{1}$, these results would need to be replicated in larger, more generalizable studies of premenopausal women before definitive conclusions can be drawn. Such studies would ideally be designed to report on botanical groupings in relation to urinary estrogen metabolites, including the 2- and $16 \alpha-\mathrm{OHE}_{1}$ in order to shed light on the particular aspects of the diet that are associated with estrogen metabolism among premenopausal women.

\section{ACKNOWLEDGEMENTS}

We would like to thank the research participants for their involvment in this project, and thank Kelly Ehrlich, Kathy Plant, and the Group Health Research Institute for screening interviews, clinic visits, and study coordination. This study was supported by NIH grant R01CA97366 and U01CA63731; KWR was supported by NIH grant K99NR012232.

\section{REFERENCES}

[1] Thomas, H.V., Reeves, G.K. and Key, T.J. (1997) Endogenous estrogen and postmenopausal breast cancer: A quantitative review. Cancer Causes and Control, 8, 922928. doi:10.1023/A:1018476631561

[2] Dallal, C. and Taioli, E. (2010) Urinary 2/16 estrogen metabolite ratio levels in healthy women: A review of the literature. Mutation Research, 705, 154-162. doi:10.1016/j.mrrev.2010.06.004

[3] Goth-Goldstein, R., Erdmann, C.A. and Russell, M. (2003) Cytochrome P4501B1 expression in normal breast tissue. Polycyclic Aromatic Compounds, 23, 259-275. doi:10.1080/10406630308051

[4] Seow, A., Vainio, H. and Yu, M.C. (2005) Effect of glutathione-S-transferase polymorphisms on the cancer preventive potential of isothiocyanates: An epidemiological perspective. Mutation Research, 592, 58-67. doi:10.1016/j.mrfmmm.2005.06.004

[5] Saracino, M.R. and Lampe, J.W. (2007) Phytochemical regulation of UDP-glucuronosyl transferases: Implications for cancer prevention. Nutrition and Cancer, 59, 121-141. doi:10.1080/01635580701458178

[6] Moon, Y.J., Wang, X. and Morris, M.E. (2006) Dietary flavonoids: Effects on xenobiotic and carcinogen metabolism. Toxicology in Vitro, 20, 187-210. doi:10.1016/j.tiv.2005.06.048

[7] Sepkovic, D.W. and Bradlow, H.L. (2009) Estrogen hydroxylation-The good and the bad. Annals of the New York Academy of Sciences, 1155, 57-67. doi:10.1111/j.1749-6632.2008.03675.x

[8] Zahid, M., et al. (2006) The greater reactivity of estradiol-3,4-quinone vs estradiol-2,3-quinone with DNA in the formation of depurinating adducts: Implications for tumor-initiating activity. Chemical Research in Toxicology, 19, 164-172. doi:10.1021/tx050229y

[9] Fishman, J. and Martucci, C. (1980) Biological properties of 16 alpha-hydroxyestrone: Implications in estrogen physiology and pathophysiology. The Journal of Clinical Endocrinology \& Metabolism, 51, 611-615. doi:10.1210/jcem-51-3-611

[10] Clark, J.H., Paszko, Z. and Peck, E.J. Jr. (1977) Nuclear binding and retention of the receptor estrogen complex: Relation to the agonistic and antagonistic properties of estriol. Endocrinology, 100, 91-96. doi:10.1210/endo-100-1-91

[11] Eliassen, A.H., et al. (2008) Circulating 2-hydroxy and 16alpha-hydroxy estrone levels and risk of breast cancer among postmenopausal women. Cancer Epidemiology, Biomarkers \& Prevention, 17, 2029-2035. doi:10.1158/1055-9965.EPI-08-0262

[12] Arslan, A.A., et al. (2009) Circulating estrogen metabolites and risk for breast cancer in premenopausal women. Cancer Epidemiology, Biomarkers \& Prevention, 18, 2273-2279. doi:10.1158/1055-9965.EPI-09-0312

[13] Ursin, G., et al. (1997) A pilot study of urinary estrogen metabolites (16alpha-OHE ${ }_{1}$ and 2-OHE 1 ) in postmenopausal women with and without breast cancer. Environmental Health Perspectives, 105, 601-605.

[14] Taioli, E., et al. (2010) Comparison of estrogens and estrogen metabolites in human breast tissue and urine. Reproductive Biology and Endocrinology, 8, 93. doi:10.1186/1477-7827-8-93

[15] Sowers, M.R., et al. (2006) Selected diet and lifestyle factors are associated with estrogen metabolites in a multiracial/ethnic population of women. Journal of Nutrition, 136, 1588-1595.

[16] Jernstrom, H., et al. (2003) Predictors of the plasma ratio of 2-hydroxyestrone to 16alpha-hydroxyestrone among pre-menopausal, nulliparous women from four ethnic groups. Carcinogenesis, 24, 991-1005. doi:10.1093/carcin/bgg047

[17] Aubertin-Leheudre, M., et al. (2008) Fat/fiber intakes and sex hormones in healthy premenopausal women in USA. The Journal of Steroid Biochemistry and Molecular Biology, 112, 32-39. doi:10.1016/j.jsbmb.2008.08.002

[18] Klug, T.L., et al. (2006) Moderate coffee and alcohol consumption improves the estrogen metabolite profile in adjuvant treated breast cancer patients: A pilot study comparing pre- and post-operative levels. Molecular Genetics and Metabolism, 89, 381-389. doi:10.1016/j.ymgme.2006.08.005

[19] Lu, F., et al. (2008) Resveratrol prevents estrogen-DNA adduct formation and neoplastic transformation in MCF10F cells. Cancer Prevention Research, 1, 135-145. doi:10.1158/1940-6207.CAPR-08-0037

[20] Ciolino, H.P., Daschner, P.J. and Yeh, G.C. (1999) Dietary flavonols quercetin and kaempferol are ligands of the aryl hydrocarbon receptor that affect CYP1A1 transcription differentially. Biochemical Journal, 340, 715-722. doi:10.1042/0264-6021:3400715 
[21] Chen, Y., et al. (2009) Simultaneous action of the flavonoid quercetin on cytochrome P450 (CYP) 1A2, CYP2A6, $\mathrm{N}$-acetyltransferase and xanthine oxidase activity in healthy volunteers. Clinical and Experimental Pharmacology and Physiology, 36, 828-833. doi:10.1111/j.1440-1681.2009.05158.x

[22] Zendulka, O., et al. (2008) The Influence of Trans-resveratrol and Quercetin on the Activity of CYP1A2 in Rat. Czech Journal of Food Sciences, 26, S60-S64.

[23] Hayes, J.D., Kelleher, M.O. and Eggleston, I.M. (2008) The cancer chemopreventive actions of phytochemicals derived from glucosinolates. European Journal of Nutrition, 47, 73-88. doi:10.1007/s00394-008-2009-8

[24] Ito, S., et al. (2007) Dietary phytochemicals regulate whole-body CYP1A1 expression through an arylhydrocarbon receptor nuclear translocator-dependent system in gut. Journal of Clinical Investigation, 117, 1940-1950. doi:10.1172/JCI31647

[25] Jellinck, P.H., et al. (1993) Ah receptor binding properties of indole carbinols and induction of hepatic estradiol hydroxylation. Biochemical Pharmacology, 45, 1129-1136. doi:10.1016/0006-2952(93)90258-X

[26] Atkinson, C., et al. (2008) Demographic, anthropometric, and lifestyle factors and dietary intakes in relation to daidzein-metabolizing phenotypes among premenopausal women in the United States. The American Journal of Clinical Nutrition, 87, 679-687.

[27] Atkinson, C., et al. (2008) Daidzein-metabolizing phenotypes in relation to serum hormones and sex hormone binding globulin, and urinary estrogen metabolites in premenopausal women in the United States. Cancer Causes and Control, 19, 1085-1093. doi:10.1007/s10552-008-9172-3

[28] Stanczyk, F.Z., et al. (2003) Limitations of direct estradiol and testosterone immunoassay kits. Steroids, 68, 1173-1178. doi:10.1016/j.steroids.2003.08.012

[29] Benjamini, Y. and Hochberg, Y. (1995) Controlling the false discovery rate: A practical and powerful approach to multiple testing. Journal of the Royal Statistical Society: Series B, 57, 289-300.

[30] Longcope, C., et al. (1987) The effect of a low fat diet on estrogen metabolism. The Journal of Clinical Endocrinology \& Metabolism, 64, 1246-1249. doi:10.1210/jcem-64-6-1246

[31] Haggans, C.J., Hutchins, A.M., Olson, B.A., Thomas, W., Martini, M.C. and Slavin, J.L. (1999) Effect of flaxseed consumption on urinary estrogen metabolites in postmenopausal women. Nutrition and Cancer, 33, 188-195. doi:10.1207/S15327914NC330211

[32] Lu, L.J., et al. (2000) Increased urinary excretion of 2-hydroxyestrone but not 16alpha-hydroxyestrone in premenopausal women during a soya diet containing isoflavones. Cancer Research, 60, 1299-1305.

[33] Bradlow, H.L., et al. (1994) Long-term responses of women to indole-3-carbinol or a high fiber diet. Cancer Epidemiology, Biomarkers \& Prevention, 3, 591-595.

[34] Mazur, W.M., et al. (2000) Phyto-oestrogen content of berries, and plasma concentrations and urinary excretion of enterolactone after a single strawberry-meal in human subjects. British Journal of Nutrition, 83, 381-387.

[35] Kristal, A.R., Peters, U. and Potter, J.D. (2005) Is it time to abandon the food frequency questionnaire? Cancer Epidemiology, Biomarkers \& Prevention, 14, 2826-2828. doi:10.1158/1055-9965.EPI-12-ED1

[36] Yang, Y.J., et al. (2010) Relative validities of 3-day food records and the food frequency questionnaire. Nutrition in Clinical Practice, 4, 142-148.

[37] Day, N., et al. (2001) Epidemiological assessment of diet: A comparison of a 7-day diary with a food frequency questionnaire using urinary markers of nitrogen, potassium and sodium. International Journal of Epidemiology, 30, 309-317. doi:10.1093/ije/30.2.309

[38] Westerlind, K.C., Gibson, K.J. and Wolfe, P. (1999) The effect of diurnal and menstrual cyclicity and menopausal status on estrogen metabolites: Implications for disease-risk assessment. Steroids, 64, 233-243. doi:10.1016/S0039-128X(98)00081-6

[39] Bradlow, H.L., et al. (2006) Comparison of plasma and urinary levels of 2-hydroxyestrogen and 16 alpha-hydroxyestrogen metabolites. Molecular Genetics and Metabolism, 87, 135-146. doi:10.1016/j.ymgme.2005.08.001

[40] Williams, A.E., et al. (2002) The temporal reliability of serum estrogens, progesterone, gonadotropins, SHBG and urinary estrogen and progesterone metabolites in premenopausal women. BMC Womens Health, 2, 13. 